
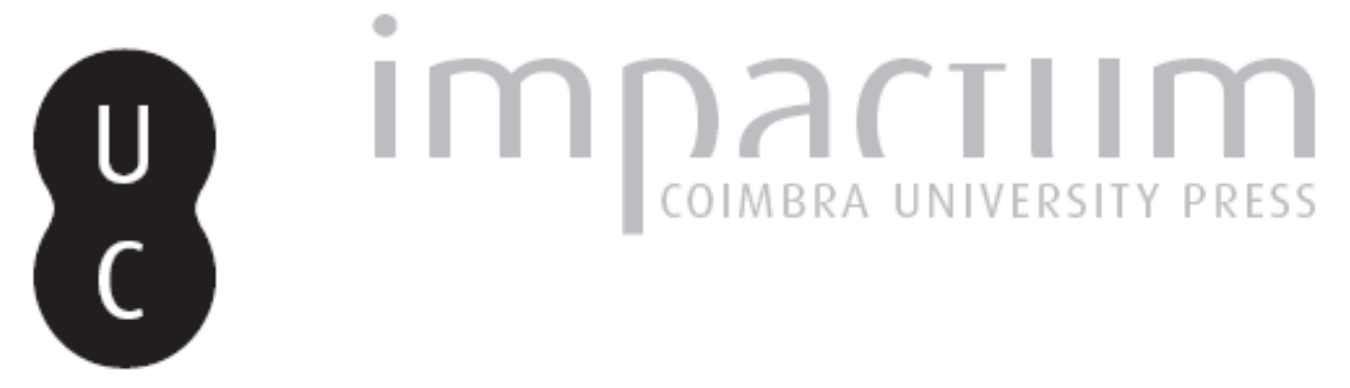

\title{
Recordação de Eudoro de Sousa
}

\section{Autor(es): $\quad$ Serra, Ordep}

Publicado por: Annablume Clássica; Imprensa da Universidade de Coimbra

URL persistente:

URI:http://hdl.handle.net/10316.2/24350

DOI:

DOI:http://dx.doi.org/10.14195/1984-249X_8_14

Accessed : $\quad$ 26-Apr-2023 12:21:47

A navegação consulta e descarregamento dos títulos inseridos nas Bibliotecas Digitais UC Digitalis, UC Pombalina e UC Impactum, pressupõem a aceitação plena e sem reservas dos Termos e Condições de Uso destas Bibliotecas Digitais, disponíveis em https://digitalis.uc.pt/pt-pt/termos.

Conforme exposto nos referidos Termos e Condições de Uso, o descarregamento de títulos de acesso restrito requer uma licença válida de autorização devendo o utilizador aceder ao(s) documento(s) a partir de um endereço de IP da instituição detentora da supramencionada licença.

Ao utilizador é apenas permitido o descarregamento para uso pessoal, pelo que o emprego do(s) título(s) descarregado(s) para outro fim, designadamente comercial, carece de autorização do respetivo autor ou editor da obra.

Na medida em que todas as obras da UC Digitalis se encontram protegidas pelo Código do Direito de Autor e Direitos Conexos e demais legislação aplicável, toda a cópia, parcial ou total, deste documento, nos casos em que é legalmente admitida, deverá conter ou fazer-se acompanhar por este aviso.

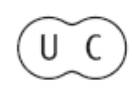


jan.2012

issn $2179-4960$

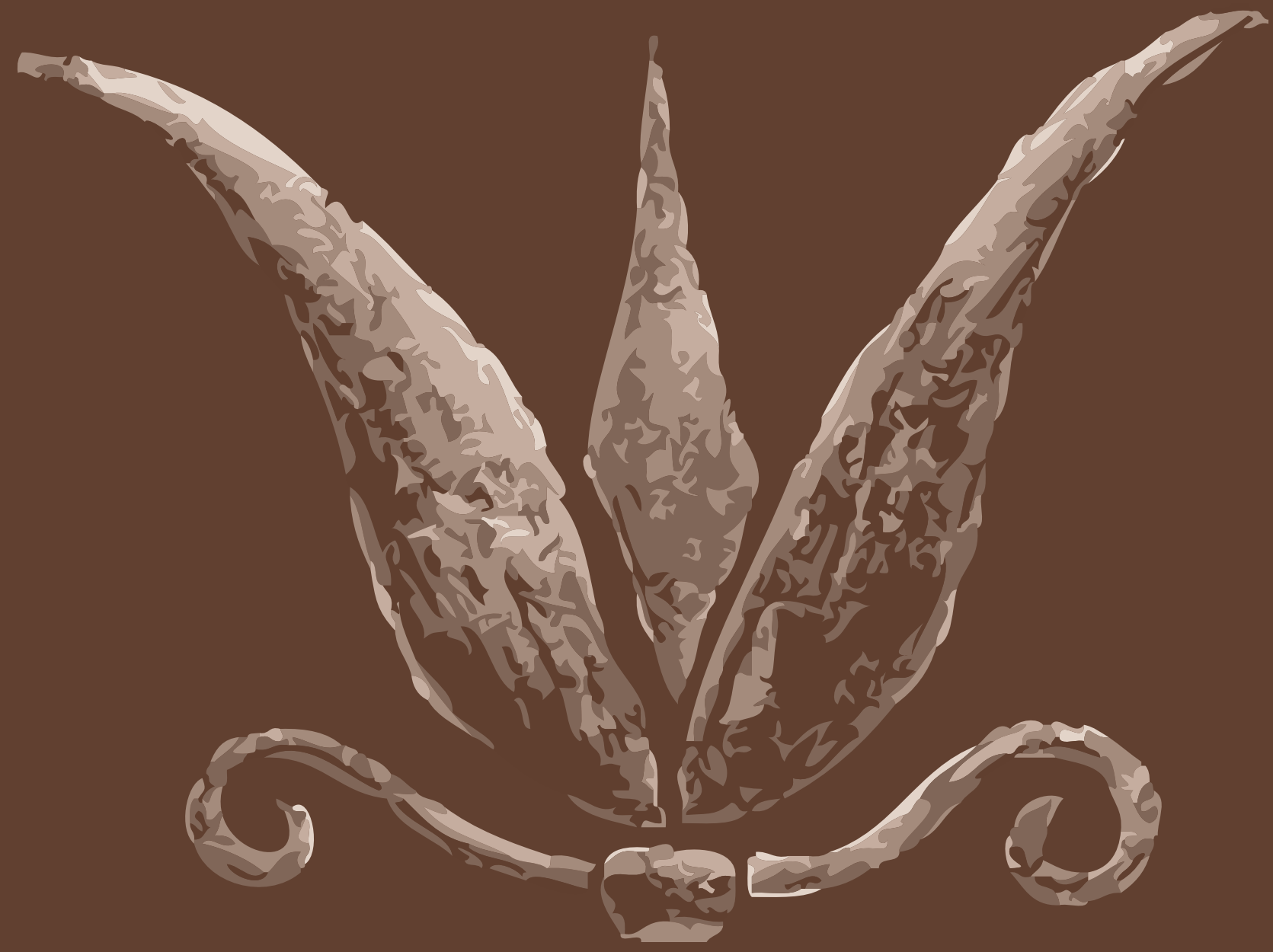

R E V I S T A
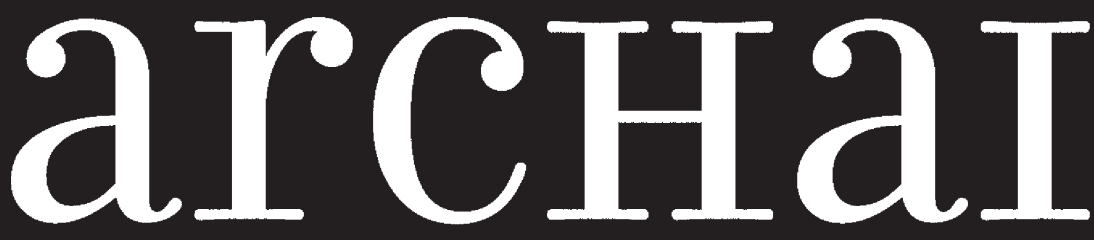

AS ORIGENS DO PENSAMENTO OCIDENTAL

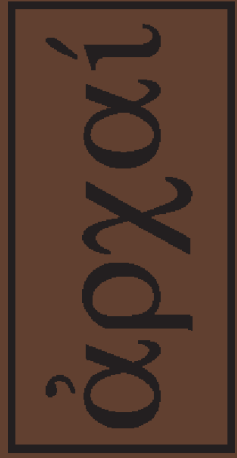

ARCHAI JOURNAL: ON THE ORIGINS OF WESTERN THOUGHT
arcHaI

AS ORIGENS DO PENSAMENTO OCIDENTA.

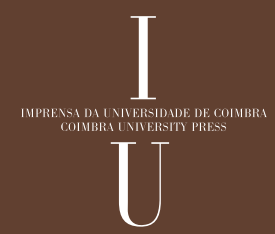

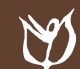




\section{RECORDAÇÃO DE EUDORO DE SOUSA}

SERRA, 0. (2012). "Recordação de Eudoro de Sousa". Archai, n. 8, jan-jun 2012, pp. 129-136.

RESUMO: Neste artigo evoco a brilhante figura do filósofo Eudoro de Sousa, assim como a breve história do Centro de Estudos Clássicos (CEC) que ele fundou na Universidade de Brasília. Destaco o papel de Eudoro como mestre, a importância de seu ensinamento e a a originalidade de seu pensamento.

PALAVRAS-CHAVE: Eudoro de Sousa, Centro de Estudos Clássicos da Universidade de Brasília, "Horizonte e Complementariedade"

ABSTRACT: In this article, I evoke the brilliant figure of the philosopher Eudoro de Sousa and his role as founder of the short-lived but productive Centro de Estudos Clássicos (Center of Classic Studies) in the University of Brasilia. I stress the relevance of Eudoro de Sousa's role and performance as a teacher and his originality as a thinker.

KEYWORDS: Eudoro de Sousa, Centre for Classical Studies at the Universidade de Brasilia, "Horizonte e Complementariedade"
* Universidade Federal da Bahia. Salvador. Bahia.

\section{Ordep Serra*}

Lembro-me bem do meu primeiro encontro com o Professor Eudoro de Sousa. Eu me preparava para fazer o vestibular que me daria acesso ao Instituto de Letras da UNB, mas meu objetivo maior era justamente estudar com ele, no Centro de Estudos Clássicos. Seguia o conselho de um homem ilustre, o Professor Agostinho da Silva, com quem eu fizera amizade na Bahia: “Eudoro é o mestre de que você precisa."

0 retrato que tenho deste mestre mostra-o tal como o conheci. Contemplando a velha fotografia, sinto ainda o brilho dos olhos agudos que pareciam desafiar-me com benévola ironia, quando a ele me apresentei. Eudoro perguntou-me porque eu me interessava pelos clássicos; falei que Virgílio me tinha fascinado e que eu precisava ler Homero no original. Este "precisar" arrancou-lhe um sorriso. Revelei-lhe ainda que sentia uma curiosidade muito grande pelo mundo greco-romano, mas principalmente pelo pensamento dos filósofos, pela arte e poesia dos gregos. Confessei ainda que tinha apenas uma ideia vaga do que fosse a filologia clássica. Diante disso, ele imediatamente foi buscar um livro que pôs nas minhas mãos: "Volta cá depois de teres lido". Isso foi pela manhã; voltei no fim da tarde para devolver o livro e saí com outro. E com uma exigência nova: “Escreve um pouco sobre o que andas 
a ler!" A isso me apliquei: a ler e fazer comentários sobre os livros e artigos que ele me indicava. Eudoro passava os olhos rapidamente pelos meus escritos e me apresentava novos textos. Na véspera do vestibular, ele me ponderou: “Tu passastes este tempo estudando o que te dei a ler; aqui não te preparaste para esses estúpidos exames, mas vê se passas! Só assim te posso receber cá no Centro, pois o tenho ligado ao Instituto. Andarás a fazer letras, vê se as desenhas bem..."

Tão logo fui aprovado e me matriculei, ele empenhou-se em conseguir-me uma bolsa. A partir de então, praticamente me internei no CEC. Dedicava a maior parte do meu tempo à aprendizagem do grego, a assistir atentamente as aulas do mestre Eudoro sobre as culturas clássicas, a seguir o roteiro de leituras que ele continuou a traçar-me, a frequentar os seminários dirigidos por ele e a acompanhar as lições de seus assistentes, que muito me ajudaram (destaco meu conterrâneo e amigo Xavier Carneiro, de quem tive sempre um caloroso apoio, um grande estímulo). No CEC estavam minhas prioridades... Tenho o diploma de Bacharel em Letras Brasileiras; mas se então me perguntassem o que eu fazia na UNB, eu responderia simplesmente: "estudo no CEC com o professor Eudoro de Sousa".

Isto não significa que lá fiquei isolado, fechado, sem contacto com o resto da Universidade. Se o fizesse, estaria contrariando o meu orientador e o espírito do Centro que ele concebeu. Tive na UNB um rico diálogo com muitos professores e colegas não apenas do Instituto de Letras como também de outras unidades e áreas. A UNB, quando lá cheguei, tinha um desenho que propiciava esses diálogos. E o CEC vinha a ser efetivamente um núcleo interdisciplinar, com estudiosos que transitavam por diferentes espaços acadêmicos. Eudoro não conseguiu torná-lo tão independente quanto queria; mas este centro não se limitou a servir ao Instituto de Letras. Seu Coordenador deu aulas sobre a matemática dos helenos e sobre história da ciência antiga a estudantes da área de Exatas; o professor João Evangelista, ligado ao CEC, ensinava no Instituto Central de Artes, onde também atuou Fernando Bastos; na área de Humanas, além do próprio Eudoro, atuou o Professor Emanuel de Oliveira Araújo. Dei aulas à maior turma de língua grega que se formou na UNB já nos últimos tempos do CEC: uma turma de estudantes de ciências da saúde, interessados em entender melhor o vocabulário médico. 0 CEC era frequentado por professores e estudantes de diferentes cursos. E queria seu fundador que ele ficasse a serviço da Universidade como um todo.

Isso não significa que ele considerasse menor o papel exercido pelo Centro no Instituto de Letras, de onde the vinha a principal demanda (por cursos de Língua e Literatura Grega, Latim e Literatura Latina, principalmente). Ele insistia, porém, em combater uma visão "beletrista" da Antiguidade Clássica. E pretendia montar uma equipe que atuasse em diferentes campos. A isso o inclinavam seu espírito aberto e seu interesse por diferentes ramos do conhecimento - interesse que convivia muito bem com sua dedicação aos estudos clássicos, entendidos com a amplitude caracerística da concepção de Classische Altertumswissenschaft haurida na vertente germânica de sua formação.

Eudoro manteve por toda a vida um gosto bem cultivado pela matemática e pela física, principalmente pela astrofísica. Era astrônomo amador e chegou a construir, junto com outros aficionados, um pequeno observatório astronômico no campus da UNB. Era seu hobby. Acima de tudo, porém, ele se via como um helenista: um estudioso do mundo grego, com forte vocação filosófica, um profundo sentimento da história. Na Alemanha, ensinou literatura portuguesa... enquanto se dedicava à filologia clássica; foi também docente de filologia românica, tanto na Europa como no Brasil. Mas a cultura helênica ocupava o centro de sua atenção intelectual.

0 primeiro curso dele a que assisti teve 0 título de "Arqueologia do Egeu e do Mediterrâneo Oriental". Tratou da formação da oikouméne mediterrânea, do seu background pré e proto-histórico. Eudoro entendia que os estudos das culturas clássicas deviam manter forte conexão com as pesquisas sobre as outras civilizações mediterrâneas, levar em conta as complexas redes de relações entre as sociedades e modos de vida que ali floresceram. Não por acaso, ele acabou recrutando para os quadros do CEC um egiptólogo, Emanuel Araújo, que fez mestrado e doutorado sob sua orientação. (Eudoro 
também despertou em mim um duradouro interesse pelas civilizações mesopotâmicas, pelas criações sumero-acadianas. Graças ao que aprendera com ele, pude, mais tarde, desfrutar melhor das lições do grande assiriólogo Jean Bottéro, em um breve curso na USP e nas conversas que mantive com este sábio em Paris).

Ouvindo as preleções de Eudoro de Sousa em muitas outras oportunidades, pude verificar a que ponto esse filólogo perito na exegese de textos escritos desenvolveu uma especial sensibilidade hermenêutica através do estudo de processos de interpretação arqueológica, de "leitura" arqueológica. E já naquele primeiro curso me dei conta da amplitude do foco de suas investigações, da profundeza com que ele encarava o seu campo de pesquisas predileto: um campo correspondente ao vasto domínio histórico ao qual Toynbee aplicou a designação de "helenismo" (envolvendo o mundo grego, o helenístico e o greco-romano).

Outro grande tema de sua reflexão veio a ser a relação entre mito e filosofia. E como se sabe, ele foi também um especialista em Aristóteles, um grande estudioso da obra de Platão e dos chamados pré-socráticos. Acho mesmo que o valor de suas traduções de fragmentos dos pré-socráticos ainda não foi devidamente reconhecido. Parece-me que, em nossa língua, ninguém as superou.

Eram muito concorridos os cursos de Eudoro de Sousa, tanto os regulares quanto os de extensão, que atraíam sempre um grande público. Ele sabia exprimir-se de maneira a um tempo luminosa e apaixonada, que prendia seu auditório, muito embora ele falasse sobre temas cuja alta complexidade jamais minimizava ou tentava disfarçar. Detestava a "clareza" simplificadora... Mas sabia como ninguém estimular a inteligência de seus ouvintes, que se sentiam gratificados por um ganho não só de conhecimento como também de lucidez.

Dele recebi poucas lições de língua grega, pois em geral ele delegava este ensino a seus assistentes. Mas essas poucas lições foram inesquecíveis. Certa feita, ele passou todo o tempo da aula a comentar um verso da Ilíada. Não se deteve na explicação gramatical do fraseado, aliás muito simples; explorou profundamente os múltiplos sentidos de duas palavras e, partindo de uma sentença, acabou por apresentar uma bela reflexão sobre o todo do poema. Eu o segui quando ele saiu da sala; sacrifiquei a aula que teria em seguida, em outra disciplina, para ouvir mais sobre esse verso, sobre os escólios que ocasionou e sobre composição dos hinos homéricos. Horas depois, ele arrematou: “agora, segue lendo; tens aí uma boa gramática, um valente dicionário. Se tiveres dúvidas, pergunta". E eu fiz como ele dizia; tinha a impressão de que se havia aberto uma clareira no corpo do texto e dali o poema se franqueava inteiro para mim.

Minhas leituras de autores gregos foram frequentemente enriquecidas pelas consultas que eu the fazia; às vezes, elas provocavam longas conversas entusiásticas, que raramente se detinham no ponto cujo esclarecimento eu the pedia. Essas conversas podiam acontecer em diferentes momentos, onde e quando eu o encontrava disponível: não raro à saída do CEC, ou no barzinho ao pé da 0 ca, enquanto ele saboreava uma cerveja. Muitas aconteceram no próprio centro; ao me ver entretido no estudo de textos clássicos ele se aproximava e perguntava-me: "Como anda isso?" Era o mote que eu tratava de aproveitar. Mas podiam acontecer pequenas complicações... Embora isso muito me instruísse - e divertisse - , acabei tendo de evitar a leitura das comédias de Aristófanes nesse local, quando Eudoro estava por perto e não muito ocupado. É que eu sempre disparava a rir - e, invariavelmente, ele acudia para saber de que eu estava rindo; quando eu the mostrava o trecho, ele o lia com entusiasmo, depois empenhava-se em traduzi-lo "com força" para o português, recitando os impagáveis versos entre gargalhadas. Ato contínuo, punha-se a comentar a passagem, de maneira nem um pouco discreta: em termos dignos de Aristófanes... para escândalo das bibliotecárias e de outras pessoas pudicas por acaso presentes. Um compenetrado professor de língua portuguesa pareceu-me particularmente ofendido ao testemunhar, por acaso, uma desses momentos aristofânicos de minha aprendizagem com Eudoro: depois desse dia, nunca mais apareceu no CEC. Em outra ocasião, quase sufoco tentando conter o riso, pois lá se achavam muitas damas, entre as quais D. Maria Luisa, a esposa do mestre. E eu lia a 
Lisístrata... Por pouco não provoco uma pequena tempestade conjugal.

0 modo como Eudoro me guiou em leituras decisivas, participando do encanto que me fazia desfrutar, foi talvez o que mais me aproximou dele. Segundo creio, é pelo encanto que melhor se aprende... Posso dizer que devo a esse mestre entusiástico minha formação intelectual. Nos seminários por ele organizados no CEC não eram discutidos apenas os clássicos gregos e romanos, mas também outros grandes autores que refletiram sobre a antiguidade ou fizeram iluminar-se algum aspecto da paideia clássica, do thesaurus da civilização greco-romana: poetas como Dante Alighieri, Hölderlin e Fernando Pessoa, por exemplo, e filósofos da cepa de Hegel, Schelling, Nietzsche, Heidegger... Esses seminários the serviam para aprofundar as reflexões que desenvolvia na construção de seu próprio pensamento filosófico. Pois ele era também um filósofo. Sua obra bem o mostra, muito embora ele não reivindicasse esse título.

Na Alemanha, Eudoro privou da amizade de Karl Jaspers e assistiu a seminários de Heidegger. (Este, entre os modernos, foi o pensador que mais o marcou). No Brasil, no período em que viveu na capital paulista, Eudoro integrou o chamado “Grupo de São Paulo", que se reunia em torno da revista Diálogo e do Instituto Brasileiro de Filosofia, sob a liderança de Vicente Ferreira da Silva, de quem ele se tornou muito amigo; Ferreira da Silva foi, sem dúvida, o autor brasileiro que mais o influenciou.

No Centro de Estudos Clássicos da UNB cultivou-se também a reflexão filosófica. Eudoro teve entre seus orientandos José Xavier Carneiro, que fez uma dissertação sobre Apolônio de Rodes, e Fernando Bastos, que dissertou sobre a teogonia de Ferécides de Siro (no doutorado, Bastos tratou da obra de seu mestre e mostrou a importância da contribuição deste para a filosofia). Xavier Carneiro era também estudioso do pensamento de Kierkgaard e teve um papel importante no Seminário sobre - Das Ding de Heidegger, que Eudoro presidiu no CEC. Mais tarde haveria de voltar-se para a filosofia oriental. Bastos dedicou-se principalmente à estética, que posteriormente lecionou por longo tempo na UNB.
Um amigo que muito o apoiou e com quem Eudoro manteve, até o fim, um diálogo criativo foi Agostinho da Silva, como ele, nascido em Portugal e naturalizado brasileiro. Tinham, os dois, estilos muito diferentes de pensar e agir, temperamentos quase opostos; mas sempre se entenderam muito bem. Agostinho teve um papel importante no CEC, para onde levou seus amigos baianos (Xavier, Jair Gramacho, Emanuel e eu mesmo); chegou a dirigi-lo por um curto período, em que Eudoro esteve afastado da função de Coordenador por problemas de saúde. Agostinho tornou-se conhecido por suas obras sobre a literatura e a cultura portuguesa (seu livro sobre Fernando Pessoa marcou época), mas também atuou em muitos outros campos: realizou pesquisas de entomologia, ensinou Filosofia do Teatro na UFBA, fundou um Centro de Estudos Afro-Orientais etc.

Em sua vasta obra, encontram-se estudos sobre assuntos os mais variados. Esse versátil polígrafo era um notável latinista; atestam-no suas magníficas traduções de Virgílio, Plauto, Terêncio. Sua amizade com Eudoro remontava a Portugal, mas aprofundou-se aqui. Ambos participaram da fundação da Universidade Federal de Santa Catarina, onde travaram importante colaboração. Agostinho também fez parte do "Grupo de São Paulo" e, tal como Eudoro, manteve forte ligação de amizade com Vicente e Dora Ferreira da Silva (a esposa do filósofo, poeta consagrada, falecida há coisa de três anos; seu belo Hídrias, onde há muita inspiração helênica, valeu-lhe em 2005 o Prêmio Jabuti). Na UnB, Agostinho fundou o Centro Brasileiro de Estudos Portugueses, deu aulas no Instituto de Letras e sempre colaborou com Eudoro de Sousa no CEC. Viajava muito; nas viagens mais demoradas, escrevia a Eudoro cartas em um latim rebuscado. Eudoro respondia em grego. Divertiam-se com isso.

Nos anos em que lá estudei, o Centro de Estudos Clássicos era um importante núcleo irradiador cuja influência se fazia sentir em toda a Universidade. Os estudantes de Biblioteconomia, de que muitos foram alunos de Eudoro, lá encontravam ensinamentos e fontes que thes facultavam compreender melhor a história do livro, por exemplo; jovens interessados em filosofia, antropologia, música, artes plásticas, letras etc. (como Pedro Agostinho, Rafael Bastos, 
Rinaldo Rossi, Olympio Serra, Hermano Penna e muitos outros) eram assíduos na biblioteca do CEC, onde costumavam assistir seminários e palestras. Quando Carlos Petrovich foi à UnB para uma tentativa de lá implantar um Curso de Teatro, teve pronto apoio de Eudoro de Sousa, que então fez uma série de conferências sobre tragédia grega no Auditório Dois Candangos e leu em primeira mão, para um vasto público, a sua tradução de As Bacantes, de Eurípides. Um amplo leque de atuação era o que o fundador sonhava quando implantou o Centro de Estudos Clássicos na UnB. Por algum tempo, conseguiu realizar este sonho...

0 CEC instalou-se primeiro em um barracão, no começo heroico; depois passou a uma ampla sala no subsolo do edifício em que funcionava a Reitoria. Tinha um belo acervo de livros e micro-filmes; uma pequena mapoteca; umas amplas mesas de reuniões no espaço principais, a cuja volta os seminários internos aconteciam; um gabinete em que o Coordenador ficava rodeado por fartas estantes, recheadas com livros que the pertenciam e tinham fichário especial, mas também por obras de referência e outras a cujo estudo ele se dedicava mais constantemente. Em bureaus destacados se instalavam os demais professores, as bibliotecárias e o pessoal da secretaria. 0 espaço todo era bem movimentado, com um afluxo constante de gente estudiosa, à procura de livros, revistas, informações. Uma saleta abrigava os monitores. Eudoro de Sousa a visitava quase todos os dias; lá me passou muitos exercícios de grego. Ali, costumava deixar, de quando em quando, livros e artigos sobre minha mesa, com a indicação do dia em que deveríamos conversar a respeito. Acabou por forçar-me a aprender alemão, pois nem sempre Xavier podia acudir-me quando nosso mestre me deixava frente a frente com textos na língua, por ele estimada indispensável, a quem "quer meter-se com Filologia Clássica". Nessa bendita saleta, tive esplêndidas aulas informais e fiz leituras inesquecíveis.

As apostilas de grego ficavam guardadas em um pequeno armário. Antes que fosse adquirida uma máquina datilográfica com caracteres em grego, o poeta Jair Gramacho praticamente desenhou os textos que eram mimeografados e distribuídos aos iniciantes no estudo desta língua. 0 leitor de microfilmes era uma grande máquina preta, um pouco sinistra, que apelidei de Libitina. Ficavam em um armário especial as estampas com reproduções de pinturas de vasos gregos e fotos de monumentos, estátuas, relevos, sigilos, moedas; além dos livros especializados, essas fotos e estampas eram muito úteis para familiarizar-nos com a iconografia helênica, romana e greco-romana. Estudantes de arquitetura e artes plásticas sempre apareciam à procura desse material.

Os bolsistas do CEC tanto estudavam como trabalhavam lá. E o trabalho era parte da aprendizagem... Muito aprendi com a simples arrumação da biblioteca.

0 CEC tinha ainda um anexo: uma copa, com um imenso bule, sempre cheio de café, entronizado em um discreto fogareiro. Com esse bule, o professor Eudoro teve, certa vez, um pequeno desentendimento, em um dia em que foi pessoalmente servir-se e queimou a mão: indignado, disparou contra o miserável uma fantástica enxurrada de xingamentos. Mas não foi rancoroso: perdoou logo o infeliz e aderiu gostosamente às minhas risadas.

Sim, ele tinha um temperamento forte; de vez em quando estourava em magníficas explosões de fúria. Em geral, elas eram provocadas por manifestações de estupidez ou de má fé. Às vezes, porém, eram inexplicáveis, beirando o absurdo, como no caso que narrei. Mas nunca envolviam perfídia, nem verdadeira malevolência. Vinham de um homem franco que não escondia suas emoções e tampouco alimentava rancores.

Eu preferia vê-lo furioso, como acontecia nos bons tempos, imprecando contra o besteirol, disposto a atacar gigantes e moinhos de vento, a fazer tempestades no cerrado seco ou em copos de uísque; preferia vê-lo assim a encontrá-lo abatido, melancólico, acabrunhado - como por vezes ele me pareceu, depois da extinção do CEC. É verdade que nesse último período ele ainda deu ótimas aulas de grego e de História Antiga, escreveu belos ensaios, estimulou alunos a produzir bons trabalhos... Mas seu sonho universitário estava destruído.

Dói-me contemplar-lhe, nas últimas fotografias, o rosto sofrido, emoldurado por uma barba que 
the deu feição de máscara trágica. Nessas fotos, seus olhos faiscantes me aparecem como lágrimas luminosas, mal contidas sob o peso sombrio das pálpebras. Sei bem do conforto que lhe dava a força pujante de seu pensamento; a fantástica lucidez que ele às vezes maldizia por certo também the deu amparo. Mas foi muito injusta a retribuição que ele teve no final da vida por um trabalho generoso em prol do desenvolvimento da cultura em nosso país.

Darcy Ribeiro e Anísio Teixeira tudo fizeram para reunir, na UnB, o que encontraram de melhor no meio universitário nacional. Sonhavam constituir aí uma nova vanguarda da inteligência brasileira. Darcy levou Agostinho da Silva para Brasília a fim de que lá ele fosse "a presença de Portugal". Na UFSC recrutou Eudoro de Sousa, a quem deu a missão de implantar no cerrado candango os estudos clássicos. Eudoro empenhou-se profundamente no trabalho que the foi confiado. Criou logo o CEC no campus poeirento da universidade em construção. 0 primeiro passo foi a formação de uma biblioteca especializada. 0 segundo foi povoá-la com estudiosos de boa cepa. 0 CEC começou logo a atuar, oferecendo cursos de graduação e pós-graduação, com um pequeno grupo de mestres que ali se reuniram sob o comando do coordenador.

Uma boa biblioteca, com espaços adequados à pesquisa erudita, à reflexão, ao exame de documentos, onde os estudantes e pesquisadores possam reunir-se, consultar-se uns aos outros, desenvolver projetos e trabalhar à vontade, isoladamente ou em equipe, é tudo de que se precisa para o funcionamento de um núcleo dessa natureza, tanto mais produtivo quanto maiores forem sua abertura interdisciplinar e seu dinamismo. Quando cheguei ao Centre Louis Gernet para um estágio, muito tempo depois, senti-me em casa. 0 CLG ainda funcionava, então, na simpática Rue Monsieur le Prince, em acomodações modestas. A rigor, era uma biblioteca especializada com uma grande mesa na sala principal, onde os estudantes ficavam a ler; tinha uma secretaria, um gabinete do diretor, espaços reservados para o uso dos pesquisadores do quadro da casa, bibliotecárias a postos, recursos de apoio ao estudo e à consulta dos livros, das revistas, dos registros iconográficos etc. Guardadas as proporções, nosso velho CEC da UnB foi concebido da mesma maneira. Pena que esse modelo tão simples e eficaz não tenha tido vida mais longa na UnB.

Como se sabe, esta Universidade sofreu muito com o golpe de 1964. Foi invadida, pouco depois da implantação do governo militar, numa verdadeira operação de guerra. Eu testemunhei essa invasão estapafúrdia. Deu-se em um dia em que se fazia a mudança do CEC, do barracão onde primeiro se instalou para as salas do subsolo da Reitoria. Cheguei a ser detido, enquanto transportava as apostilas de grego. Um zeloso soldado desconfiou de que se tratava de material subversivo: "Veja, sargento, isso parece russo!" 0 sargento, menos estúpido, logo se deu conta do absurdo da hipótese de estar alguém distribuindo panfletos em russo por ali e mandou-me andar - um tanto incomodado, também, pelo meu sorriso divertido em meio a toda aquela confusão. Foi meu primeiro contacto com o febeapá da "gloriosa".

Outras invasões se sucederam, sempre com detenção de estudantes e professores, submetidos à violência e ao arbítrio que passaram a ser normais no triste regime. Costumo dizer que até hoje, ao passar pela quadra de basket-ball que há no campus da UnB, tenho o impulso de cruzar as mãos atrás da nuca: era assim que conduziam para lá os suspeitos, nessas invasões; e mais de uma vez me aconteceu de ser suspeito...

Conhece-se bem a história da grande crise que afetou esta universidade em 1965, quando o reitor designado pelo governo militar resolveu fazer nela um indecente expurgo, começando pela demissão sumária e injustificada de um mestre. Em reação a essa medida, demitiram-se de uma só vez duzentos e vinte e três professores. Esperava-se criar um grande impasse... Mas o governo os substituiu depressa, recrutando a torto e direito todo tipo de docente disponivel, sem maiores preocupações com a qualidade. Parte dos demissionários acabou por sair do país; essa evasão de cérebros foi um dos graves danos causados ao Brasil pela ditadura. Os bons professores que resolveram ficar na UnB foram, em diferentes momentos, muito "patrulhados" por isso. Mas creio que sua decisão de permanecer e resistir impediu o total desmoronamento da instituição. Se 
não o fizessem, seria mais rápida, fácil e completa a vitória do obscurantismo, com efeitos quiçá irreversíveis na alma mater brasiliense.

Eudoro ficou. Caso ele não tivesse ficado, mais cedo se teria acabado o CEC, sem deixar as sementes que deixou; muitos estudantes teriam perdido a oportunidade de formar-se com seus ensinamentos e sua sábia orientação; pesquisas e teses valiosas não se teriam concluído; um tesouro de inteligência e cultura nos escaparia e a UNB ficaria sem uma de suas grandes estrelas, que ainda muito britho the havia de conferir. Creio que pesou na decisão de Eudoro um elemento importante: ele já se considerava brasileiro e não queria deixar sua nova pátria. Tampouco queria desistir da universidade tão sonhada, de que foi um dos fundadores. Pagou caro por este sonho...

0 CEC resistiu ainda por alguns anos; mas logo a mão de ferro do obscurantismo o atacaria brutalmente. Apontado por um energúmeno - um espião disfarçado de professor, um pseudo-intelectual que o invejava profundamente -, Eudoro de Sousa foi indiciado como subversivo e respondeu a um inquérito policial militar. Ele não tinha atividade política, mas era clara sua simpatia pelos estudantes sempre rebelados; gostava de assistir às assembléias da FEUB (Federação dos Estudantes da Universidade de Brasília) e era amigo de seu presidente, Honestino Guimarães, líder estudantil mais tarde assassinado pela repressão. 0 canalha que dedurou Eudoro foi expulso da universidade pelos estudantes, que ocuparam o apartamento da Colina onde residia o pretenso docente e fizeram seu despejo, em um dos episódios mais singulares da conturbada história da UnB. No local foram encontrados documentos do verdadeiro serviço do "professor" de araque. Numa sua agenda estava anotado: “Denunciar o Coordenador Eudoro". A imprensa local divulgou o acontecimento (esse registro inclusive).

Por falta de provas, Eudoro não foi preso. Foi apenas fichado... Mas os seus colaboradores do CEC logo viriam a ser atingidos por medidas arbitrárias do interventor que ocupava a reitoria da UnB nesses anos de chumbo. Em 1968, o Professor Xavier Carneiro foi desligado sem que the dissessem o motivo. 0 CEC foi extinto. Quando de sua extinção, o latinista Suetônio Valença e eu, que então fazíamos o mestrado, tivemos nossas bolsas cortadas e nossas matriculas anuladas sem qualquer explicação. 0 belo acervo do CEC foi transferido para uma sala obscura da Biblioteca Central (custa-me crer que está todo ali).

Eudoro continuou a dar aulas, mas vivia quase isolado na sua Universidade. Tinha ainda por perto Emanuel Araújo, no Departamento de História, e Fernando Bastos no Instituto Central de Artes (Emanuel passou uma temporada na cadeia, por militar contra a ditadura); também se tornou um seu amigo próximo Ronaldes de Melo e Sousa, brilhante teórico da literatura, que com ele estudou grego.

Quando voltei à Unb para fazer pós-graduação em Antropologia Social, retomei o diálogo com o velho mestre. Tivemos um belo debate a propósito de seu livro "Horizonte e Complementariedade" (que também resenhei para o Anuário Antropológico). Em resposta a indagações que the fiz a respeito desta obra, de que destaquei a forte originalidade, Eudoro apresentou uma leitura dela que contradizia uma das teses centrais aí defendidas; já a tinha superado... Mostrei-lhe essa contradição e ele reagiu com surpresa. Publicou o nosso diálogo no seu "Sempre o Mesmo acerca do Mesmo", escrito, como ele afirmou, para responder a meu questionamento. Foi uma resposta muito rica; orgulho-me de a ter provocado. Eudoro sentiu-se um tanto espicaçado por ver-se na condição de "mau leitor de si mesmo", segundo suas palavras. Mas o que eu evidenciei foi o avanço de um pensamento muito rico, que ultrapassava uma alta posição alcançada em seu movimento ascendente.

Concluído o meu mestrado em Antropologia Social, voltei para Salvador; depois disso, poucas vezes estive com Eudoro, em rápidas passagens por Brasília. Não acompanhei a última etapa de sua vida e de sua produção. Lendo-o de longe, a uma distância já impossível de percorrer, sinto ainda 0 vigor criativo que transparecia em sua voz nos velhos tempos. E até me parece que nosso diálogo nunca se interrompeu.

Recebido em novembro de 2011. Aprovado em dezembro de 2011. 